\title{
Modulatory effects on dendritic cells by human herpesvirus 6
}

\author{
Rasmus Gustafsson ${ }^{1 *}$, Mattias Svensson ${ }^{2}$ and Anna Fogdell-Hahn ${ }^{3}$ \\ ${ }^{1}$ Department of Molecular Medicine and Surgery, Karolinska Institutet, Karolinska University Hospital, Stockholm, Sweden, \\ ${ }^{2}$ Department of Medicine, Center for Infectious Medicine, Karolinska Institutet, Karolinska University Hospital, Stockholm, \\ Sweden, ${ }^{3}$ Department of Clinical Neuroscience, Karolinska Institutet, Karolinska University Hospital, Stockholm, Sweden
}

Human herpesvirus 6A and 6B are $\beta$-herpesviruses approaching $100 \%$ seroprevalance worldwide. These viruses are involved in several clinical syndromes and have important immunomodulatory effects. Dendritic cells (DC) are key players in innate and adaptive immunity. Accordingly, DC are implicated in the pathogenesis of many human diseases, including infections. In this review the effects of HHV-6 infection on DC will be discussed.

\section{OPEN ACCESS}

Edited by: Michael McVoy, Virginia Commonwealth University,

Reviewed by:

Masaki Yasukawa, Ehime University Graduate School of Medicine, Japan Jaime Mauricio Calvo-calle, University of Massachusetts, USA

${ }^{*}$ Correspondence:

Rasmus Gustafsson, Karolinska Institutet, Karolinska University Hospital, Solna, L2:05,

17176 Stockholm, Sweden rasmus.gustafsson@ki.se

Specialty section: This article was submitted to Virology,

a section of the journal Frontiers in Microbiology

Received: 23 February 2015 Accepted: 15 April 2015 Published: 30 April 2015

Citation:

Gustafsson R, Svensson $M$ and Fogdell-Hahn A (2015) Modulatory effects on dendritic cells by human herpesvirus 6. Front. Microbiol. 6:388.

doi: 10.3389/fmicb.2015.00388
Keywords: HHV-6, dendritic cells, activation, cytokines, HLA, co-stimulatory molecules

\section{Introduction}

Human herpesvirus 6 (HHV-6) is a ubiquitous $\beta$-herpes virus that most people have been exposed to by the age of 2 years (Okuno et al., 1989; Ward et al., 1993; Hall et al., 1994; Zerr et al., 2005). It was first isolated in the mid 80's from patients with lymphoproliferative disorders and acquired immunodeficiency syndrome (Salahuddin et al., 1986; Downing et al., 1987; Tedder et al., 1987). HHV-6 isolates are classified into two distinct virus species, HHV-6A and 6B (Ablashi et al., 2014). This review discusses the effect of HHV-6 on dendritic cells (DC).

The primary infection of HHV-6 usually gives mild fever and in a limited number of cases also a rash (Pruksananonda et al., 1992). The infection typically appear from 6 months of age, when the immune protection from the mother vanishes and before the immune system of the child is fully established (Stone et al., 2014). However, the virus can also cause fatal encephalitis as primary infection (Yamamoto et al., 2014), but typically this occurs only in immuno compromised patients due to, for example, induced immunosuppression after transplantation (Zerr et al., 2012). As an opportunistic infection the virus has been detected in different organs like heart (Hakacova et al., 2013; Escher et al., 2015) and tyroidea (Caselli et al., 2012). The reactions seen during the HHV-6 associated drug-reaction with eosinophilia and systemic symptoms syndrome show that reactivation of the virus can occur from multiple tissues and organs (Cacoub et al., 2011). There are also indications of involvement in CNS diseases like multiple sclerosis (Virtanen and Jacobson, 2012) and epilepsy (Theodore et al., 2008; Esposito et al., 2014), although these results have been difficult to verify in cross-sectional studies (Gustafsson et al., 2013a; Engdahl et al., 2014).

The viruses may have tropism for many different cell types, including immune cells. A predominant tropism is seen for CD4+ T cells (Lusso et al., 1988; Takahashi et al., 1989), but also CD8+ T cells (Lusso et al., 1991; Grivel et al., 2003), NK cells (Lusso et al., 1993), monocytes (Kondo et al., 1991; Niiya et al., 2006), macrophages (Kondo et al., 1991), and DC (Asada et al., 1999; Hirata et al., 2001; Kakimoto et al., 2002; Niiya et al., 2004; Takemoto et al., 2009). However, the role of HHV-6 interactions with host DC in the pathogenic events of HHV-6 infection remains unclear. 


\section{Dendritic Cells}

DC are a heterogeneous family of cells with specialized antigen presenting capacities (Banchereau and Steinman, 1998; Schlitzer and Ginhoux, 2014). They can engulf extracellular material such as bacteria and virions, subsequently degraded in lysosomes. DC respond to microbial stimuli, such as pathogen-associated molecular patterns that are bound by pattern recognition receptors such as toll-like receptors (TLR) (Kaisho and Akira, 2006). DC also respond to inflammatory stimuli, such as inflammatory cytokines. Microbial and inflammatory stimuli can initiate a process of cellular activation termed maturation. The process of maturation is associated with increased surface levels of MHC and co-stimulatory molecules and other surface markers such as CD83, as well as enhanced production of soluble inflammatory mediators such as type I IFN, interleukin (IL)-8, IL-6, tumor necrosis factor (TNF), and IL-12 (Ueno et al., 2007).

In the orchestration of T cells, DC interact with the TCR on the $\mathrm{T}$ cells using its major histocompatibility complex (MHC) molecules that binds antigenic peptides. The co-stimulatory molecules CD80, CD86, and CD40 on the DC further strengthen the interactions by binding to their ligands CD28 and CD40L on the $\mathrm{T}$ cells. Upon such interaction, a so called "immunological synapse" is formed and signals are transmitted to the $\mathrm{T}$ cells (Huppa and Davis, 2003). Generally, MHC class I binds endogenous antigens (peptides) synthesized in the cells while MHC class II binds exogenous antigens engulfed by endocytic processes. Exogenous peptides are also presented on MHC-I in a process called cross-presentation (Van Montfoort et al., 2014). While DC together with B cells and macrophages, have the ability to express both MHC class I and class II molecules and consequently interact with both CD4 $+\mathrm{T}$ cells and CD8 $+\mathrm{T}$ cells, most other cells only express MHC class I. Viruses can hijack the replication machinery of host cells, and hence, the virusinfected cell displays viral peptides on its MHC class I molecules to allow interaction with CD8 $+\mathrm{T}$ cells leading to killing of the infected cells. In humans, MHC is termed human leukocyte antigen (HLA).

The two major sub groups of DC are plasmacytoid (pDC) and classical (cDC), and the $\mathrm{cDC}$ refer to all $\mathrm{DC}$ other than $\mathrm{pDC}$ (Merad et al., 2013). Pre-cDCs derive from common DC progenitors and migrate from the bone marrow via the blood and home to lymphoid and non-lymphoid tissues (Liu et al., 2009). Also, monocytes can differentiate into cDCs in vivo mainly in infected or inflamed tissues, and therefore monocytes have been viewed as precursors of inflammatory DC (Naik et al., 2006). Recent studies, however, have established that monocytes contribute to intestinal (Bogunovic et al., 2009; Varol et al., 2009), splenic (Lewis et al., 2011), and muscular cDC also at steady state (Langlet et al., 2012).

Although in vitro culturing of human CD34+ progenitors with the Flt3L and thrombopoietin has proven useful in generating both pDC and cDC (Chen et al., 2004; Poulin et al., 2010), the dominant model for the generation of human DC has involved culturing monocytes with colony-stimulating factor 2 (CSF-2) and IL-4, which primarily produces dermal-like CD1a+ cDC (Sallusto and Lanzavecchia, 1994; Palucka et al.,
1998). CSF-2-stimulated cultures reliably produce large numbers of monocyte-derived DC (MDC), which is invaluable when designing experiments to study the functional consequences of pathogen interactions with host DC in human infections.

\section{Virus Replication}

The vast majority of studies investigating HHV-6A or $6 \mathrm{~B}$ infection in DC have studied MDC. The literature provides contradictory reports on the replication capacity of HHV-6A (Hirata et al., 2001; Smith et al., 2005; Gustafsson et al., 2013b) (Table 1). Whereas, Hirata et al. (2001) suggests that DC can support HHV6A (U1102 strain) replication by increase in protein load over time, Smith et al. (2005) suggests that DC cannot support HHV6A (GS strain) replication as no increase in intracellular viral DNA was seen over time. We did not detect any increase in either viral protein or DNA when infecting DC with HHV-6A (GS strain) (Gustafsson et al., 2013b), thus supporting the report by Smith et al. To control for degraded virus or suboptimal infections both Smith et al. and we infected susceptible cells in parallel with DC using the same virus supernatants. Productive infection was seen in the susceptible cells suggesting that lack of viral replication seen in DC was not due to problems with the virus stock or infection procedure. Hence, the discordant results might lay in other factors such as the different viral strains or passages used. Whereas U1102 strain showed productive infection, GS strain did not.

For HHV-6B, the literature is more consistent. This is seen by different read-outs including increased virus titers in supernatants over time (Asada et al., 1999), detection of virus proteins using immunofluoresence staining (Asada et al., 1999; Hirata et al., 2001) or flow cytometry; and detection of viral mRNA expression (Kakimoto et al., 2002; Niiya et al., 2006; Takemoto et al., 2009). Assessing the presence of viral proteins is somewhat problematic given the difficulty to discriminate between viral proteins from the inoculum or from de novo virus synthesis, as it is not feasible to completely wash away virus particles after inoculation. An alternative approach is to assess shifts in levels of viral DNA (Asada et al., 1999). Translation of early and late HHV6B genes has been seen, however, Takemoto et al. (2009) detected few virions and thereby conclude that replication in DC might be incomplete. However, transmission to allogenic matured CD4+ $\mathrm{T}$ cells upon co-culture was seen, and conversion to productive replication via cell-to-cell contact (Takemoto et al., 2009). This was not seen for HHV-6A (Gustafsson et al., 2013b). In conclusion, DC seem to be able to support a productive infection of HHV-6B and transmit the virus to $\mathrm{T}$ cells, constituting an important vector for transporting the virus to the most susceptible cell type. For HHV-6A, more studies are needed and the positive result shown should be repeated using other viral strains or clinical isolates to provide more robust proof of tropism.

\section{Immune Modulation}

\section{HLA}

Among the various aspects of immunomodulation, HHV-6 has been suggested to impair differentiation of monocytes to DC 


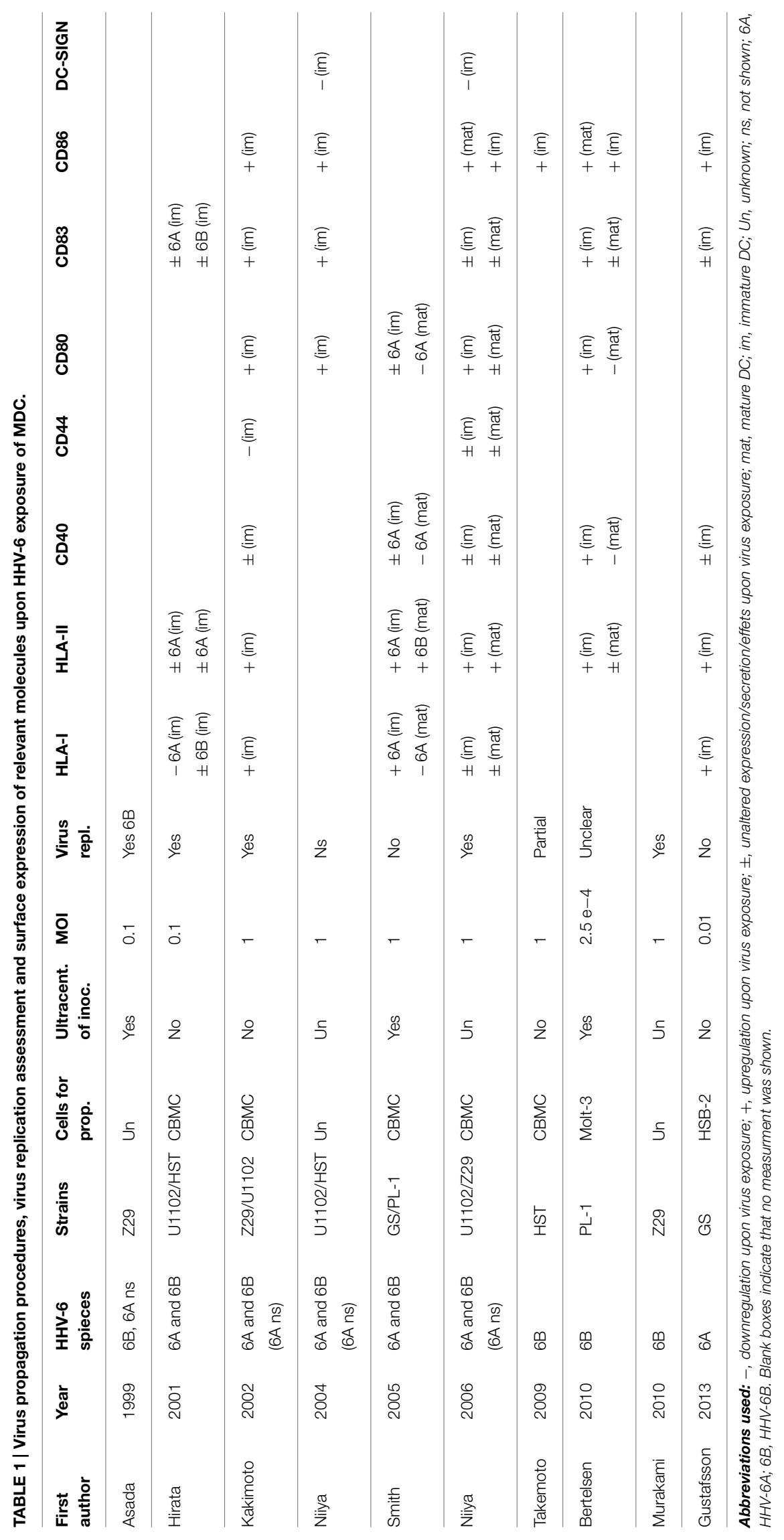


(Niiya et al., 2006). The effects on DC, however, remain controversial (Table 1). Whereas some studies report up-regulation of HLA class I on immature DC upon exposure to HHV-6A or $6 \mathrm{~B}$, both with or without virus replication (Kakimoto et al., 2002; Smith et al., 2005; Gustafsson et al., 2013b) others have shown virus replication-dependent down-regulation for HHV$6 \mathrm{~A}$ but not for 6B (Hirata et al., 2001), and some have shown no effect at all (Niiya et al., 2006). In our hands HLA class I expression was induced by autocrine IFN- $\alpha$ signaling (Gustafsson et al., 2013b). Two studies have investigated the expression on matured DC and demonstrated down-regulation or unaltered expression (Smith et al., 2005; Niiya et al., 2006). These differences are explained neither by the cell type used for virus propagation nor by whether ultracentrifugation on virus inoculum was used or not. Likewise, presence or absence of virus replication cannot explain the conflicting results. Another drawback in comparisons with older studies is that sometimes the specific virus species used for a certain experiment is not described, probably as HHV-6A and HHV-6B was recognized as two separate viruses as late as in 2014. The same inconsistency is seen for HLA class II upon HHV-6A and HHV-6B infection where some studies report up-regulation; some report down-regulation and some show an unaltered expression (Hirata et al., 2001; Kakimoto et al., 2002; Smith et al., 2005; Niiya et al., 2006; Bertelsen et al., 2010; Gustafsson et al., 2013b). To conclude, despite the elegant pioneering study by Hirata et al. that convincingly showed a HHV-6A exclusive suppressive effect on HLA class I, the effects on HLA I/II expression does not seem to be very strong given the varying results in subsequent studies.

\section{Co-stimulatory Molecules and Other Surface Markers}

Regarding co-stimulatory molecules a vast majority of studies report conclusive data for up-regulation of CD86 and unaltered expression of CD40 on immature DC (Kakimoto et al., 2002; Smith et al., 2005; Niiya et al., 2006; Gustafsson et al., 2013b), regardless of virus replication. Also for mature DC, CD86 is up-regulated whereas CD40 expression is suppressed by both HHV-6A and 6B (Smith et al., 2005; Bertelsen et al., 2010). For $\mathrm{CD} 80$ a productive virus replication of $\mathrm{HHV}-6 \mathrm{~B}$ seems to lead to up-regulation in immature DC (Kakimoto et al., 2002; Niiya et al., 2004; Bertelsen et al., 2010), whereas mature DC down-regulate CD80 upon exposure with or without replication for both HHV6A and 6B (Smith et al., 2005; Bertelsen et al., 2010). CD83 is unaltered or up-regulated upon infection with both viruses and on both immature and matured DC. Hence, independent of productive replication, neither $\mathrm{HHV}-6 \mathrm{~A}$ nor $6 \mathrm{~B}$ seems to suppress the functions of DC on the level of co-stimulatory molecules but rather induce maturation and activation.

Dendritic Cell-Specific Intercellular adhesion molecule-3Grabbing Non-integrin (DC-SIGN) and CD44 are cell surface molecules that are important for DC homing and $\mathrm{T}$ cell maturation. One study suggests that DC-SIGN is down-regulated by replicating $\mathrm{HHV}-6 \mathrm{~A}$ and $6 \mathrm{~B}$, as $\mathrm{UV}$ inactivation of the virus prior to inoculation abrogated the suppressive effect (Niiya et al., 2004). Similarly, CD44 was suppressed or unaltered on DC upon HHV-6 infection (Kakimoto et al., 2002; Niiya et al., 2006). Thus, HHV-6 might have suppressive effects on the ability of DC to bind tissues such as endothelium.

\section{Cytokines}

Interferon (IFN) type I and III are important mediators of antiviral immunity, secreted upon virus infection, and they have a range of different effects. Interferon- $\alpha$ and $-\lambda$ both signal via the Janus kinase-signal transducers and activators of transcription pathway but they utilize different cell surface receptors (Sheppard et al., 2003; Gibbert et al., 2013). Whereas HHV-6B exposure can induce both IFN- $\alpha$ and $-\lambda$ secretion by pDC (Nordstrom and Eriksson, 2012), HHV-6A exposure induces strong IFN- $\alpha$,

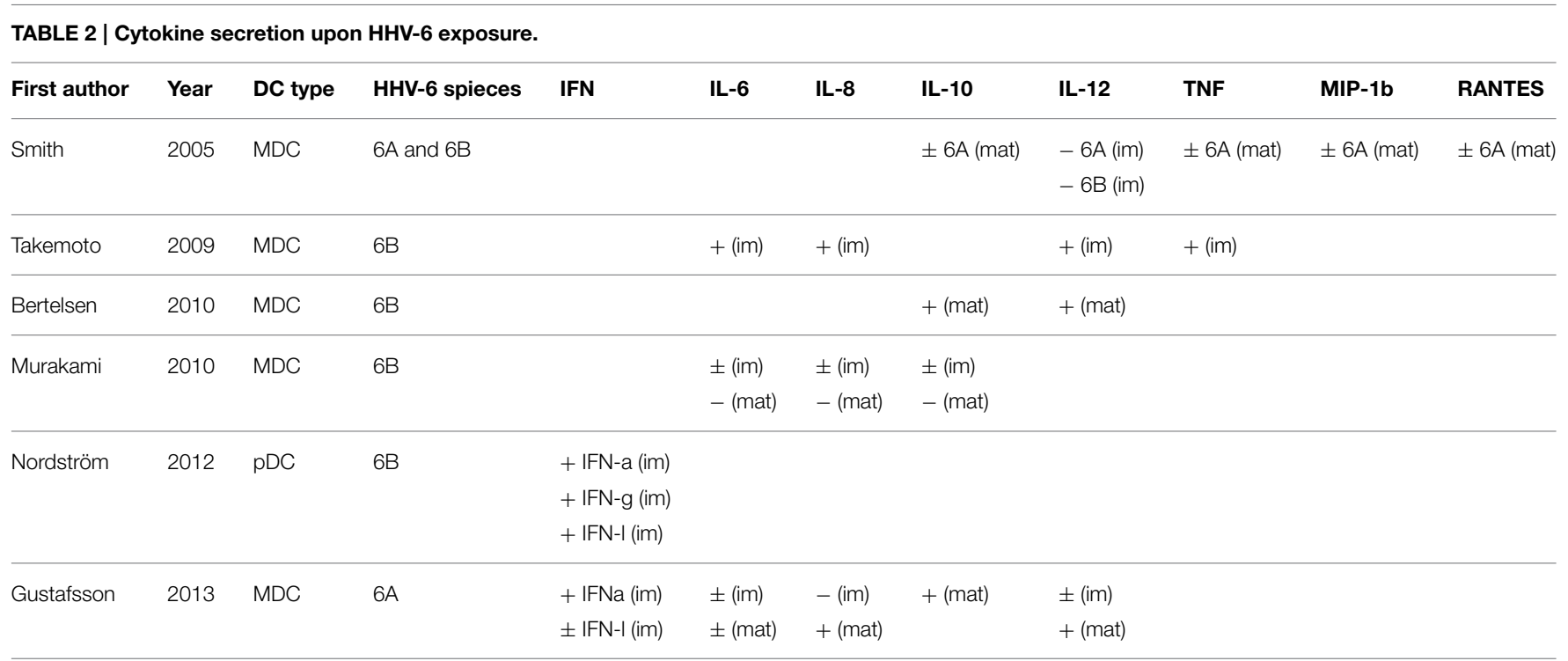

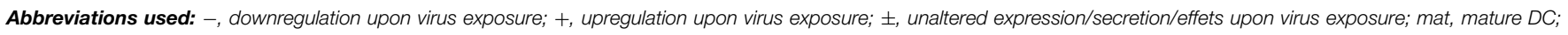
im, immature DC; 6A, HHV-6A; 6B, HHV-6B. Blank boxes indicate that no measurment was shown. 
but low IFN- $\lambda$ secretion by MDC (Gustafsson et al., 2013b) (Table 2).

IL-12 is involved in the differentiation of T cells toward a Th1 lineage. Suppression of IL-12 secretion upon non-productive infection of both HHV-6A and 6B has been shown to occur both in DC (Smith et al., 2005) and macrophages (Smith et al., 2003). The opposite effect in DC with augmented levels has been seen for both HHV-6A (Gustafsson et al., 2013b) and HHV-6B (Bertelsen et al., 2010). Reasons for this divergence is unclear but at least does not seem to lie in the procedures used for virus propagation as the two studies demonstrating augmented secretion used crude supernatant or ultracentrifuged virus. The data on IL-12 described above was generated on mature DC. In immature DC the secretions are much more modest with a slight increase (Takemoto et al., 2009) or undetectable secretion (Smith et al., 2005; Gustafsson et al., 2013b). Possibly, therefore the role of IL-12 may not be of major importance for immunity against HHV-6, but this needs to be investigated further.

TNF secretion can be induced by IL-12 (Nagayama et al., 2000). Three studies have looked at TNF secretion and report conflicting results that however, at least in part, can be explained by the IL-12 profiles. Whereas the single study that report modest increased secretion of TNF by immature DC upon productive HHV-6B infection also see increased IL-12 secretion (Takemoto et al., 2009), we and others saw unaltered and nearly undetectable levels of TNF, along with IL-12 upon non-productive HHV-6A infection, as described above (Smith et al., 2005; Gustafsson et al., 2013b). Hence, the different results might be explained by the use of different viruses and/or virus replication. In matured DC, however, the levels of TNF are more dramatic. In line with the IL-12 profiles described above we see augmented secretion of TNF (Gustafsson et al., 2013b) whereas Smith et al. (2005) see unaltered or slightly decreased secretion.

IL-6 secretion is important in acute phases of inflammation. Whereas immature DC slightly up-regulated IL-6 secretion upon HHV-6B infection and replication (Takemoto et al., 2009), mature DC down-regulated secretion, due to impaired TLR4 signaling (Murakami et al., 2010). For HHV-6A minute levels were secreted by immature DC, and for mature DC the virus somewhat augmented the secretion (Gustafsson et al., 2013b). Therefore, HHV-6B might have an exclusive ability to suppress TLR4 signaling that is not seen for HHV-6A, in terms of IL-6 secretion, but this potential difference between the virus strains remains to be tested.

IL-8 is a crucial cytokine which induces migration of neutrophils across vascular walls (Atta Ur et al., 1999). HHV-6A has been shown to strongly suppress IL-8 secretion in immature DC, but this effect was overridden when other stimuli such as lipopolysaccharides and IFN- $\gamma$ was present (Gustafsson et al., 2013b). HHV-6B displays a mirror image with slightly enhanced secretion by immature DC (Takemoto et al., 2009) but suppressed secretion by mature DC (Murakami et al., 2010). As for IL-6, described above, an exclusive ability of HHV-6B to suppress TLR4 signaling might explain these differences.

The ability to control immune responses to restore tissue homeostasis is crucial for the organism. IL-10 has anti-inflammatory properties and suppresses secretion of inflammatory cytokine and expression of HLA class II and co-stimulatory molecules. Whereas HHV-6A inoculation does not affect IL-10 secretion in mature DC (Smith et al., 2005), inconsistent data for HHV-6B has been published with down- or up-regulation (Bertelsen et al., 2010; Murakami et al., 2010). Hence, additional studies are needed to clarify the role of IL-10 in HHV-6 infection.

\section{T Cell Stimulation}

The capacities of DC to stimulate T cell expansion is crucial and the literature is quite consistent with four out of five studies showing a reduced allostimulatory capacity upon inoculation (Asada et al., 1999; Kakimoto et al., 2002; Smith et al., 2005; Niiya et al., 2006; Gustafsson et al., 2013b) (Table 3). This effect is seen for $\mathrm{HHV}-6 \mathrm{~A}$ as well as for HHV-6B, regardless of virus replication, and therefor the evidence is strong. The two studies assessing the effect on autologous $\mathrm{T}$ cell activation both observed an impaired capacity upon inoculation with both HHV-6A and 6B (Kakimoto et al., 2002; Niiya et al., 2006). This effect was also seen in vivo, as demonstrated by an elegant experiment where allogenic $\mathrm{T}$ cells were co-cultured with MDC from a patients with drug induced hypersensitivity syndrome during HHV-6 viremia and recovery phases. The allostimulatory capacity was clearly reduced during viremia (Niiya et al., 2006). HHV-6 also seems to possess more indirect suppressive effects by the induction of virus specific Tregs which can accomplish a suppression of the maturation of MDC in vivo (Wang et al., 2014).

\section{Conclusions and Future Perspectives}

Altered cytokine secretion profiles, suppressed expression of costimulatory molecules and HLA molecules and cytopathic effects

\begin{tabular}{|c|c|c|c|c|}
\hline First author & Year & $\begin{array}{l}\text { HHV-6 } \\
\text { spieces }\end{array}$ & Allostimulation & Autostimulation \\
\hline Asada & 1999 & $\begin{array}{l}6 \mathrm{~A} \text { and } 6 \mathrm{~B} \\
(6 \mathrm{~A} \mathrm{~ns})\end{array}$ & $\pm 6 \mathrm{~B}(\mathrm{im})$ & \\
\hline Kakimoto & 2002 & $\begin{array}{l}6 \mathrm{~A} \text { and } 6 \mathrm{~B} \\
(6 \mathrm{~A} \mathrm{~ns})\end{array}$ & $-(\mathrm{im})$ & $-(\mathrm{im})$ \\
\hline Smith & 2005 & $6 \mathrm{~A}$ and $6 \mathrm{~B}$ & $\begin{array}{l}-6 \mathrm{~A} \text { (mat) } \\
-6 \mathrm{~A} \text { (im) }\end{array}$ & \\
\hline Niiya & 2006 & $6 \mathrm{~A}$ and $6 \mathrm{~B}$ & $\begin{array}{l}-6 \mathrm{~A}(\mathrm{im}) \\
-6 \mathrm{~B}(\mathrm{im})\end{array}$ & $-(\mathrm{im})$ \\
\hline Gustafsson & 2013 & $6 \mathrm{~A}$ & $-(\mathrm{im})$ & \\
\hline
\end{tabular}

Abbreviations used: -, downregulation upon virus exposure; +, upregulation upon virus exposure; \pm , unaltered expression/secretion/effets upon virus exposure; mat, mature DC; im, immature DC; ns, not shown; 6A, HHV-6A; 6B, HHV-6B. Blank boxes indicate that no measurment was shown. 
in response to HHV-6 may critically impact HHV-6 pathogenesis. The ability of DC to activate and induce proliferation of $\mathrm{T}$ cells, as well as establishing appropriate cytokine milieus required for $\mathrm{T}$ cell polarization makes further studies on mechanisms underlying the suppressive effects seen by HHV-6 necessary. The literature provides consistent results on the suppressive effect of HHV-6 on T cell proliferation. In contrast, reports on the effects on cytokine secretion and surface expression of co-stimulatory and HLA molecules on DC are contradictory. Therefore, for

\section{References}

Ablashi, D., Agut, H., Alvarez-Lafuente, R., Clark, D. A., Dewhurst, S., Diluca, D., et al. (2014). Classification of HHV-6A and HHV-6B as distinct viruses. Arch. Virol. 159, 863-870. doi: 10.1007/s00705-013-1902-5

Asada, H., Klaus-Kovtun, V., Golding, H., Katz, S. I., and Blauvelt, A. (1999). Human herpesvirus 6 infects dendritic cells and suppresses human immunodeficiency virus type 1 replication in coinfected cultures. J. Virol. 73, 4019-4028.

Atta Ur, R., Harvey, K., and Siddiqui, R. A. (1999). Interleukin-8: an autocrine inflammatory mediator. Curr. Pharm. Des. 5, 241-253.

Banchereau, J., and Steinman, R. M. (1998). Dendritic cells and the control of immunity. Nature 392, 245-252. doi: 10.1038/32588

Bertelsen, L. B., Petersen, C. C., Kofod-Olsen, E., Oster, B., Hollsberg, P., Agger, R., et al. (2010). Human herpesvirus $6 B$ induces phenotypic maturation without IL-10 and IL-12p70 production in dendritic cells. Scand. J. Immunol. 71, 431-439. doi: 10.1111/j.1365-3083.2010.02389.x

Bogunovic, M., Ginhoux, F., Helft, J., Shang, L., Hashimoto, D., Greter, M., et al. (2009). Origin of the lamina propria dendritic cell network. Immunity 31, 513-525. doi: 10.1016/j.immuni.2009.08.010

Cacoub, P., Musette, P., Descamps, V., Meyer, O., Speirs, C., Finzi, L., et al. (2011). The DRESS syndrome: a literature review. Am. J. Med. 124, 588-597. doi: 10.1016/j.amjmed.2011.01.017

Caselli, E., Zatelli, M. C., Rizzo, R., Benedetti, S., Martorelli, D., Trasforini, G., et al. (2012). Virologic and immunologic evidence supporting an association between HHV-6 and Hashimoto's thyroiditis. PLoS Pathog. 8:e1002951. doi: 10.1371/journal.ppat.1002951

Chen, W., Antonenko, S., Sederstrom, J. M., Liang, X., Chan, A. S., Kanzler, H., et al. (2004). Thrombopoietin cooperates with FLT3-ligand in the generation of plasmacytoid dendritic cell precursors from human hematopoietic progenitors. Blood 103, 2547-2553. doi: 10.1182/blood-2003-09-3058

Downing, R. G., Sewankambo, N., Serwadda, D., Honess, R., Crawford, D., Jarrett, R., et al. (1987). Isolation of human lymphotropic herpesviruses from Uganda. Lancet 2, 390. doi: 10.1016/S0140-6736(87)92403-2

Engdahl, E., Gustafsson, R., Ramanujam, R., Sundqvist, E., Olsson, T., Hillert, J., et al. (2014). HLA-A $\left(^{*}\right) 02$, gender and tobacco smoking, but not multiple sclerosis, affects the IgG antibody response against human herpesvirus 6. Hum. Immunol. 75, 524-530. doi: 10.1016/j.humimm.2014.03.001

Escher, F., Kuhl, U., Gross, U., Westermann, D., Poller, W., Tschope, C., et al. (2015). Aggravation of left ventricular dysfunction in patients with biopsyproven cardiac human herpesvirus A and B infection. J. Clin. Virol. 63, 1-5. doi: 10.1016/j.jcv.2014.11.026

Esposito, L., Drexler, J. F., Braganza, O., Doberentz, E., Grote, A., Widman, G., et al. (2014). Large-scale analysis of viral nucleic acid spectrum in temporal lobe epilepsy biopsies. Epilepsia 56, 234-243. doi: 10.1111/epi.12890

Gibbert, K., Schlaak, J. F., Yang, D., and Dittmer, U. (2013). IFN-alpha subtypes: distinct biological activities in anti-viral therapy. Br. J. Pharmacol. 168, 1048-1058. doi: 10.1111/bph.12010

Grivel, J. C., Santoro, F., Chen, S., Faga, G., Malnati, M. S., Ito, Y., et al. (2003). Pathogenic effects of human herpesvirus 6 in human lymphoid tissue ex vivo. J. Virol. 77, 8280-8289. doi: 10.1128/JVI.77.15.8280-8289.2003

Gustafsson, R. K., Engdahl, E. E., Hammarfjord, O., Adikari, S. B., Lourda, M., Klingstrom, J., et al. (2013b). Human herpesvirus 6A partially suppresses functional properties of DC without viral replication. PLoS ONE 8:e58122. doi: 10.1371/journal.pone.0058122 the impairment of $\mathrm{T}$ cell proliferation, cytokines, or surface molecules may not have a major impact but may result from other factors. However, to test impacts of soluble factors, conditioned media from virus infected DC (filtered to remove virions) can be used to treat co-cultures with DC and T cells. To substantiate the findings reported so far the data should be repeated with better standardization of virus propagation procedures and comparisons between different virus strains or clinical isolates to increase the concordance between different studies.

Gustafsson, R., Reitsma, R., Stralfors, A., Lindholm, A., Press, R., and FogdellHahn, A. (2013a). Incidence of human herpesvirus 6 in clinical samples from Swedish patients with demyelinating diseases. J. Microbiol. Immunol. Infect. 47, 418-421. doi: 10.1016/j.jmii.2013.03.009

Hakacova, N., Klingel, K., Kandolf, R., Engdahl, E., Fogdell-Hahn, A., and Higgins, T. (2013). First therapeutic use of Artesunate in treatment of human herpesvirus 6B myocarditis in a child. J. Clin. Virol. 57, 157-160. doi: 10.1016/j.jcv.2013.02.005

Hall, C. B., Long, C. E., Schnabel, K. C., Caserta, M. T., McIntyre, K. M., Costanzo, M. A., et al. (1994). Human herpesvirus-6 infection in children. A prospective study of complications and reactivation. N. Engl. J. Med. 331, 432-438. doi: 10.1056/NEJM199408183310703

Hirata, Y., Kondo, K., and Yamanishi, K. (2001). Human herpesvirus 6 downregulates major histocompatibility complex class I in dendritic cells. J. Med. Virol. 65, 576-583. doi: 10.1002/jmv.2075

Huppa, J. B., and Davis, M. M. (2003). T-cell-antigen recognition and the immunological synapse. Nat. Rev. Immunol. 3, 973-983. doi: 10.1038/nri1245

Kaisho, T., and Akira, S. (2006). Toll-like receptor function and signaling J. Allergy Clin. Immunol. 117, 979-987; quiz 988. doi: 10.1016/j.jaci.2006. 02.023

Kakimoto, M., Hasegawa, A., Fujita, S., and Yasukawa, M. (2002). Phenotypic and functional alterations of dendritic cells induced by human herpesvirus 6 infection. J. Virol. 76, 10338-10345. doi: 10.1128/JVI.76.20.10338-10345. 2002

Kondo, K., Kondo, T., Okuno, T., Takahashi, M., and Yamanishi, K. (1991). Latent human herpesvirus 6 infection of human monocytes/macrophages. J. Gen. Virol. 72 (Pt 6), 1401-1408. doi: 10.1099/0022-1317-72-6-1401

Langlet, C., Tamoutounour, S., Henri, S., Luche, H., Ardouin, L., Gregoire, C., et al. (2012). CD64 expression distinguishes monocyte-derived and conventional dendritic cells and reveals their distinct role during intramuscular immunization. J. Immunol. 188, 1751-1760. doi: 10.4049/jimmunol. 1102744

Lewis, K. L., Caton, M. L., Bogunovic, M., Greter, M., Grajkowska, L. T., Ng, D., et al. (2011). Notch2 receptor signaling controls functional differentiation of dendritic cells in the spleen and intestine. Immunity 35, 780-791. doi: 10.1016/j.immuni.2011.08.013

Liu, K., Victora, G. D., Schwickert, T. A., Guermonprez, P., Meredith, M. M., Yao, $\mathrm{K}$., et al. (2009). In vivo analysis of dendritic cell development and homeostasis. Science 324, 392-397. doi: 10.1126/science.1170540

Lusso, P., Malnati, M., De Maria, A., Balotta, C., Derocco, S. E., Markham, P. D., et al. (1991). Productive infection of CD4+ and CD8+ mature human T cell populations and clones by human herpesvirus 6 . Transcriptional downregulation of CD3. J. Immunol. 147, 685-691.

Lusso, P., Malnati, M. S., Garzino-Demo, A., Crowley, R. W., Long, E. O., and Gallo, R. C. (1993). Infection of natural killer cells by human herpesvirus 6 . Nature 362, 458-462. doi: 10.1038/362458a0

Lusso, P., Markham, P. D., Tschachler, E., Di Marzo Veronese, F., Salahuddin, S. Z., Ablashi, D. V., et al. (1988). In vitro cellular tropism of human Blymphotropic virus (human herpesvirus-6). J. Exp. Med. 167, 1659-1670. doi: 10.1084/jem.167.5.1659

Merad, M., Sathe, P., Helft, J., Miller, J., and Mortha, A. (2013). The dendritic cell lineage: ontogeny and function of dendritic cells and their subsets in the steady state and the inflamed setting. Annu. Rev. Immunol. 31, 563-604. doi: 10.1146/annurev-immunol-020711-074950 
Murakami, Y., Tanimoto, K., Fujiwara, H., An, J., Suemori, K., Ochi, T., et al. (2010). Human herpesvirus 6 infection impairs Toll-like receptor signaling. Virol. J. 7:91. doi: 10.1186/1743-422X-7-91

Nagayama, H., Sato, K., Kawasaki, H., Enomoto, M., Morimoto, C., Tadokoro, K., et al. (2000). IL-12 responsiveness and expression of IL-12 receptor in human peripheral blood monocyte-derived dendritic cells. J. Immunol. 165, 59-66. doi: 10.4049/jimmunol.165.1.59

Naik, S. H., Metcalf, D., Van Nieuwenhuijze, A., Wicks, I., Wu, L., O’Keeffe, M., et al. (2006). Intrasplenic steady-state dendritic cell precursors that are distinct from monocytes. Nat. Immunol. 7, 663-671. doi: 10.1038/ni1340

Niiya, H., Azuma, T., Jin, L., Uchida, N., Inoue, A., Hasegawa, H., et al. (2004). Transcriptional downregulation of DC-SIGN in human herpesvirus 6-infected dendritic cells. J. Gen. Virol. 85, 2639-2642. doi: 10.1099/vir.0.80095-0

Niiya, H., Lei, J., Guo, Y., Azuma, T., Yakushijin, Y., Sakai, I., et al. (2006). Human herpesvirus 6 impairs differentiation of monocytes to dendritic cells. Exp. Hematol. 34, 642-653. doi: 10.1016/j.exphem.2006.02.001

Nordstrom, I., and Eriksson, K. (2012). HHV-6B induces IFN-lambda1 responses in cord plasmacytoid dendritic cells through TLR9. PLoS ONE 7:e38683. doi: 10.1371/journal.pone.0038683

Okuno, T., Takahashi, K., Balachandra, K., Shiraki, K., Yamanishi, K., Takahashi, M., et al. (1989). Seroepidemiology of human herpesvirus 6 infection in normal children and adults. J. Clin. Microbiol. 27, 651-653.

Palucka, K. A., Taquet, N., Sanchez-Chapuis, F., and Gluckman, J. C. (1998). Dendritic cells as the terminal stage of monocyte differentiation. J. Immunol. 160, 4587-4595.

Poulin, L. F., Salio, M., Griessinger, E., Anjos-Afonso, F., Craciun, L., Chen, J. L., et al. (2010). Characterization of human DNGR-1+ BDCA3+ leukocytes as putative equivalents of mouse CD8alpha+ dendritic cells. J. Exp. Med. 207, 1261-1271. doi: 10.1084/jem.20092618

Pruksananonda, P., Hall, C. B., Insel, R. A., Mcintyre, K., Pellett, P. E., Long, C. E., et al. (1992). Primary human herpesvirus 6 infection in young children. N. Engl. J. Med. 326, 1445-1450. doi: 10.1056/NEJM199205283262201

Salahuddin, S. Z., Ablashi, D. V., Markham, P. D., Josephs, S. F., Sturzenegger, S., Kaplan, M., et al. (1986). Isolation of a new virus, HBLV, in patients with lymphoproliferative disorders. Science 234, 596-601. doi: 10.1126/science.2876520

Sallusto, F., and Lanzavecchia, A. (1994). Efficient presentation of soluble antigen by cultured human dendritic cells is maintained by granulocyte/macrophage colony-stimulating factor plus interleukin 4 and downregulated by tumor necrosis factor alpha. J. Exp. Med. 179, 1109-1118. doi: 10.1084/jem.179.4.1109

Schlitzer, A., and Ginhoux, F. (2014). Organization of the mouse and human DC network. Curr. Opin. Immunol. 26, 90-99. doi: 10.1016/j.coi.2013.11.002

Sheppard, P., Kindsvogel, W., Xu, W., Henderson, K., Schlutsmeyer, S., Whitmore, T. E., et al. (2003). IL-28, IL-29 and their class II cytokine receptor IL-28R. Nat. Immunol. 4, 63-68. doi: 10.1038/ni873

Smith, A. P., Paolucci, C., Di Lullo, G., Burastero, S. E., Santoro, F., and Lusso, P. (2005). Viral replication-independent blockade of dendritic cell maturation and interleukin-12 production by human herpesvirus 6. J. Virol. 79, 2807-2813. doi: 10.1128/JVI.79.5.2807-2813.2005

Smith, A., Santoro, F., Di Lullo, G., Dagna, L., Verani, A., and Lusso, P. (2003). Selective suppression of IL-12 production by human herpesvirus 6 . Blood 102, 2877-2884. doi: 10.1182/blood-2002-10-3152

Stone, R. C., Micali, G. A., and Schwartz, R. A. (2014). Roseola infantum and its causal human herpesviruses. Int. J. Dermatol. 53, 397-403. doi: $10.1111 /$ ijd. 12310
Takahashi, K., Sonoda, S., Higashi, K., Kondo, T., Takahashi, H., Takahashi, M., et al. (1989). Predominant CD4 T-lymphocyte tropism of human herpesvirus 6-related virus. J. Virol. 63, 3161-3163.

Takemoto, M., Imasawa, T., Yamanishi, K., and Mori, Y. (2009). Role of dendritic cells infected with human herpesvirus 6 in virus transmission to CD4(+) T cells. Virology 385, 294-302. doi: 10.1016/j.virol.2008.11.049

Tedder, R. S., Briggs, M., Cameron, C. H., Honess, R., Robertson, D., and Whittle, H. (1987). A novel lymphotropic herpesvirus. Lancet 2, 390-392. doi: 10.1016/S0140-6736(87)92404-4

Theodore, W. H., Epstein, L., Gaillard, W. D., Shinnar, S., Wainwright, M. S., and Jacobson, S. (2008). Human herpes virus 6B: a possible role in epilepsy? Epilepsia 49, 1828-1837. doi: 10.1111/j.1528-1167.2008.01699.x

Ueno, H., Klechevsky, E., Morita, R., Aspord, C., Cao, T., Matsui, T., et al. (2007). Dendritic cell subsets in health and disease. Immunol. Rev. 219, 118-142. doi: 10.1111/j.1600-065X.2007.00551.x

Van Montfoort, N., Van Der Aa, E., and Woltman, A. M. (2014). Understanding MHC class I presentation of viral antigens by human dendritic cells as a basis for rational design of therapeutic vaccines. Front. Immunol. 5:182. doi: 10.3389/fimmu.2014.00182

Varol, C., Vallon-Eberhard, A., Elinav, E., Aychek, T., Shapira, Y., Luche, H., et al. (2009). Intestinal lamina propria dendritic cell subsets have different origin and functions. Immunity 31, 502-512. doi: 10.1016/j.immuni.2009.06.025

Virtanen, J. O., and Jacobson, S. (2012). Viruses and multiple sclerosis. CNS Neurol. Disord. Drug Targets 11, 528-544. doi: 10.2174/187152712801 661220

Wang, F., Chi, J., Peng, G., Zhou, F., Wang, J., Li, L., et al. (2014). Development of virus-specific CD4+ and CD8+ regulatory $\mathrm{T}$ cells induced by human herpesvirus 6 infection. J. Virol. 88, 1011-1024. doi: 10.1128/JVI.02586-13

Ward, K. N., Gray, J. J., Fotheringham, M. W., and Sheldon, M. J. (1993). IgG antibodies to human herpesvirus- 6 in young children: changes in avidity of antibody correlate with time after infection. J. Med. Virol. 39, 131-138. doi: 10.1002/jmv.1890390209

Yamamoto, W., Ogusa, E., Matsumoto, K., Maruta, A., Ishigatsubo, Y., and Kanamori, H. (2014). Human herpesvirus-6 encephalopathy after hematopoietic stem cell transplantation and class I human leukocyte antigen. Clin. Transplant. 28, 540-545. doi: 10.1111/ctr.12342

Zerr, D. M., Boeckh, M., Delaney, C., Martin, P. J., Xie, H., Adler, A. L., et al. (2012). HHV-6 reactivation and associated sequelae after hematopoietic cell transplantation. Biol. Blood Marrow Transplant. 18, 1700-1708. doi: 10.1016/j.bbmt.2012.05.012

Zerr, D. M., Meier, A. S., Selke, S. S., Frenkel, L. M., Huang, M. L., Wald, A., et al. (2005). A population-based study of primary human herpesvirus 6 infection. $N$. Engl. J. Med. 352, 768-776. doi: 10.1056/NEJMoa042207

Conflict of Interest Statement: The authors declare that the research was conducted in the absence of any commercial or financial relationships that could be construed as a potential conflict of interest.

Copyright (c) 2015 Gustafsson, Svensson and Fogdell-Hahn. This is an open-access article distributed under the terms of the Creative Commons Attribution License (CC $B Y)$. The use, distribution or reproduction in other forums is permitted, provided the original author(s) or licensor are credited and that the original publication in this journal is cited, in accordance with accepted academic practice. No use, distribution or reproduction is permitted which does not comply with these terms. 